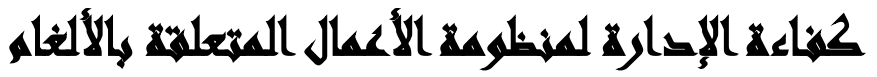

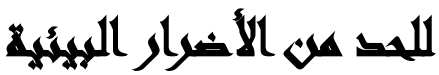

\section{$[1 \mathrm{lT}]$}

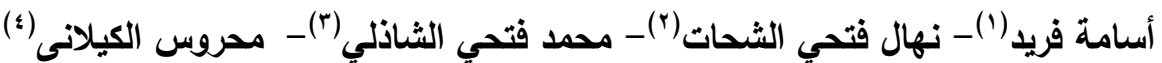

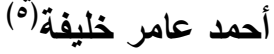

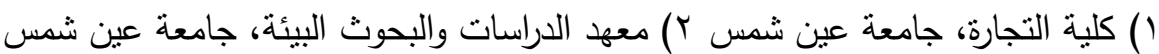

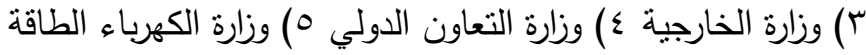

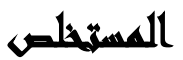

يهدف البحث إلى محاولة تقديم مفهوم الإدارة لمنظومة الأعمال المتعلقة بالألغام لحد من الأضرار والخسائر البيئية الناتجة عنها مع تقديم الحلول للتصدي لهان التها.

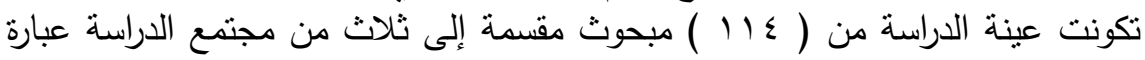

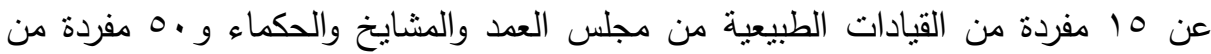

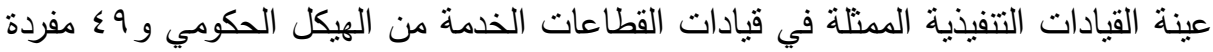
من منظمات المجتمع المدني ممثلة في أطراف المشكلة من الناجين من الألغام من خلاد الإل الجمعيات الأهلية بمنطقة الدراسة التية

واعتمدت الدراسة على المسح الاجتماعي بالعينة حيث بعنبة الإنة المستح الاجتماعي المستخدم من المناهج المناسبة للادراسة الوصفية التحليلية الاعلية

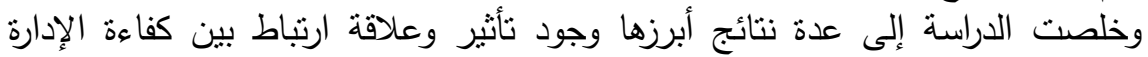

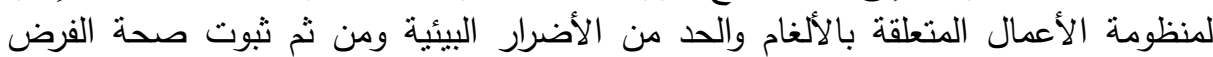

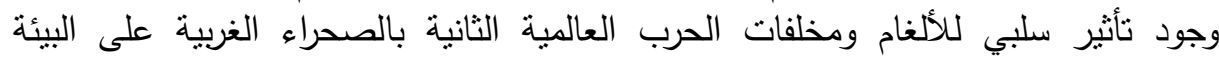

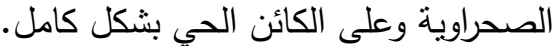

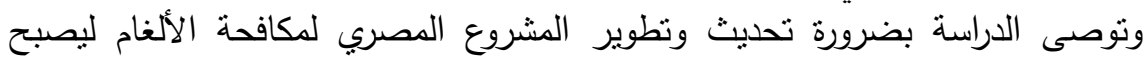

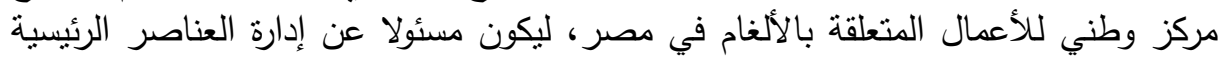

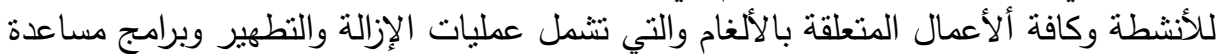

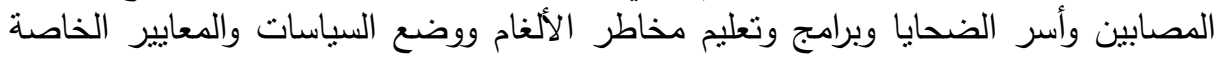

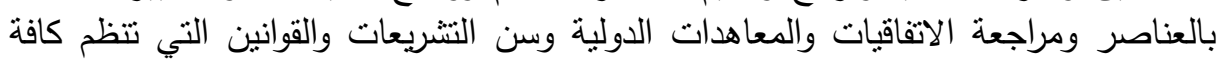

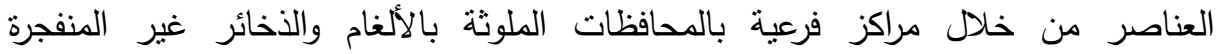
والمتفجرات الناتجة عن الحروب في كل ربول فئر مصر . 


\section{المهابs}

تشكل الألغام والمخلفات الخطرة من الذخائر والأجسام الغير منفجرة والقابلة للانفجار وغيرها الناتجة من العمليات العسكرية في المناطق التي شهدت الصراعات ( الأمانة التنفيذية

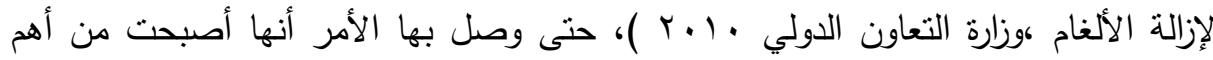
المشكلات التي تقف أمام تعزيز وحماية حقوق الإنسان. بل والكائن الحي الموجود في مناطق الصراعات على سطح كوكب الأرض، ويعتبر وجود هذه الأجسام الخطرة انتهاكا صارخاً لحقوق الإنسان (ورقة عمل مقدمة للمؤتمر العالمي حول الألغام وتتمية الساحل الثمالي،

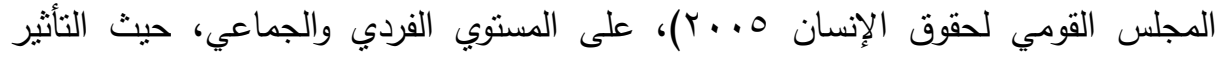
السلبي الذي يؤدي إلى الحرمان من التمتع بالحقوق الأساسية التي كفلتها المواثيق والمعاهدات والاتفاقيات الدولية كالحق في الحياة الآمنة والحق في سلامة الجسد والحق في البيئة النظيفة

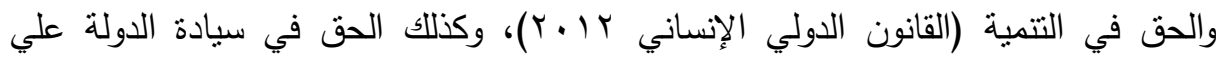
مواردها ومقدراتها والتي حالت هذه الأجسام الخطرة دون الاستفادة منها خاصة في الدول التي لإسي

$$
\text { زرعت الألغام في أراضيها رغما عنها. }
$$

\section{and 12.0.}

شهدت الصحراء الغربية ( محافظة مطروح ) بجمهورية مصر العربية النهاية المأساوية

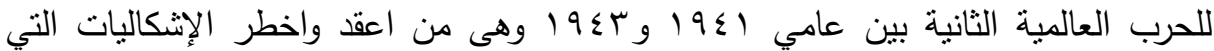
تؤثر التأثثرات السلبية في المجالات الاقتصادية والاجتماعية والبيئية ( تقرير بعثة الأمم

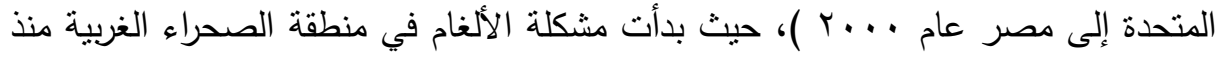
العمليات الحربية التي دارت على نطاق واسع بين دول الحلفاء ودول المحور أثناء الحرب العالمية الثانية، حيث قامت القوات البريطانية من ناحية والقوات الألمانية والايطالية من ناحية أخرى بزراعة مناطق واسعة بكثافة شديدة بالألغام تعويضا عن نقص الحواجز الطبيعية

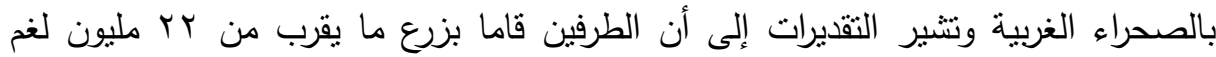
وجسم قابل للانفجار خلال تلك الفترة وبعد جهود القوات المسلحة المصرية خلال عمليات 
الإزالة منذ انتهاء الحرب إلى أن أصبح أجمالي الألغام والأجسام القابلة للانفجار ما يقرب من 17 مليون جسم وذخائر قابلة للانفجار قنابل طائرات ويدوية وقذائف (اللجنة القومية للإثراف الإلفات

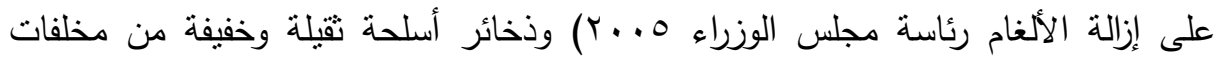

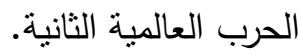

\section{توساولاهي المهمث}

تدور الدراسة حول السؤال الرئيسي وهو مدى كفاءة وفاعلية إدارة الأعمال المتعلقة

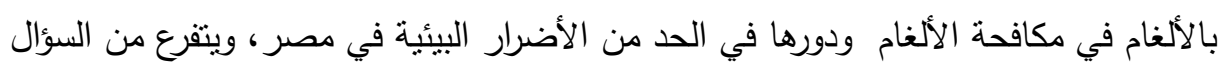

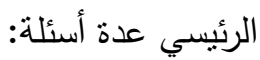

1-ما ددى تفهم إثكالية الألغام والذخائر القابلة للانفجار؟

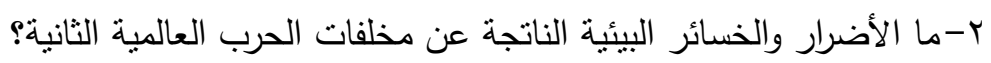
r-ما مدى أهمية دور الإدارة للحد من الأضرار والخسائر البيئية الناتجة عنها؟

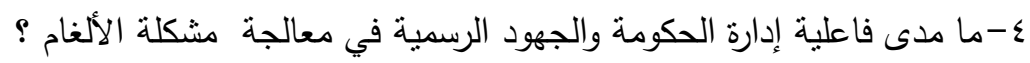
0-ما مدى فاعلية دور منظمات المجتمع المدني في معالجة الألغام ؟ مداء

\section{أهساهت المهيد}

يعدف البحث إلى الأتي: دور الإدارة وكفاءتها في منظومة الأعمال المتعلقة بالألغام وكيفية

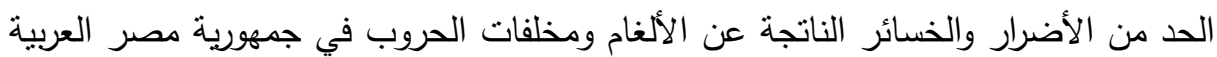

\section{هروض المهنش}

وجود تأثير سلبي للمتفجرات من مخلفات الحرب العالمية الثانية من الألغام والذخائر غير المنفجرة والذخائر المتروكة بالصحراء الغربية على البيئة الصحراوية وعلى الكائن الحي بشكل عام. 


\section{أهمية المهمث}

استمرار تأثثر الألغام ومخلفات الحرب العالمية الثانية في صحراء مصر الغربية على

البيئة بشكل كبير مع زيادة معدل الخسائر البشرية سواء في الوفيات أو الإصابة وحرمان الثعب المصري من التتمية والاستثمار منذ ما يزيد عن ه من انتهاء الحرب العالمية الثانية لمساحات شاسعة . الحاجة الملحة لتتمية واستثمار المناطق المضارة بالألغام بالصحراء الغربية والتي سوف تناهم وبشكل كبير في ارتفاع مستوى الاقتصاد المصري

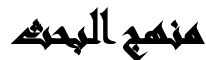

أعتمد الباحث في خطته الإستراتيجية بشكل عام والمعالجات التي تصدى لها من خلال الأتي: استخدام المنهج الاستقرائي: عن طريق الأبحاث والكتب والدوريات والدراسات السابقة والإحصاءات العربية والأجنبية التي تمت في مجال مكافحة الألغام في مصر والعالم العربي والمنظمات الدولية العاملة في هذا المجال، وذلك من اجل خدمة أهداف البحث وتوضيه فئيح العلاقات والمفاهيم ذات الصلة. استخدام المنهج التحليلي: بهدف تحليل البيانات المنوافرة حول مشكلة البحث من اجل الوقوف على العلاقات بين متغيرات الدراسة

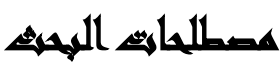

مفاهيم متعلقة بعلم إدارة الأعمال المتعلقة بالألغام:

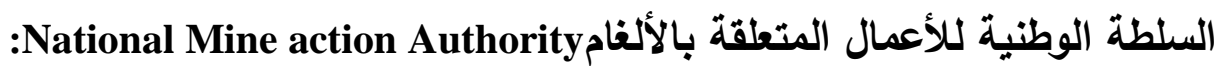
وهو مركز رئيسي وطني معنى بكافة الأنشطة المتعلقة بمكافحة الألغام في البلد، وعبارة عن الدائرة أو المنظمة أو المؤسسة الحكومية في كل بلد من البلدان المتضررة من مخاطر الألغام ومخلفات الحروب وتكون معنية بتقنين الأعمال المتعلقة بالألغام وإدارة وتتسيق كافة الأنشطة المرتبطة بالأعمال المتعلقة بمكافحة الألغام ،ويتكفل المركز الوطني للأعمال المتعلقة بالألغام 
بالمسؤولية عن التخطيط والتتفيذ والمتابعة وتعبئة الموارد ويقوم بمهام الهيئة الوطنية للأعمال

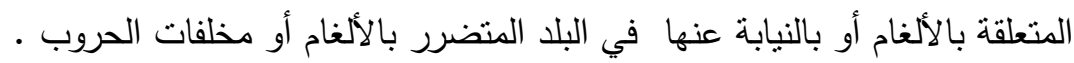
مركز الأعمال المتعلقة بالألغام Mine action center: هو عبارة عن مركز تتسيق

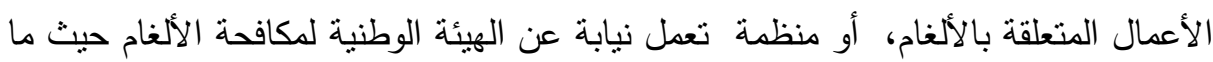
كانت موجودة، عادة هي المسئولة عن التخطيط والتتسيق والأشراف وتتفيذ المشاريع وتتكفل

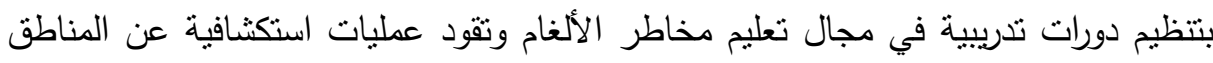

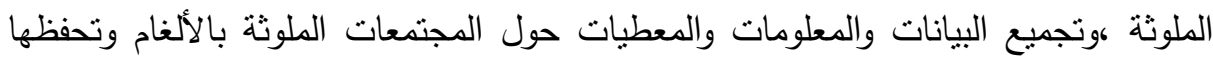
في المركز وتتسق بين المخططات المحلية وأنشطة الوكالات الخارجية في مجال إزالة الألغام ويؤدى المكتب دور المكتب التشغيلي للسلطة الوطنية أو المركز الوطني الرئيسي للأعمال المتعلقة بالألغام التابع للاولة.

الأعمال المتعلقة بالألغام Mine action: وفقا لتعريف الأمم المتحدة والوارد في المعايير الدولية للأعمال المتعلقة بالألغام، فإن الأعمال المتعلقة بالألغام تنشير إلي "الأنشطة

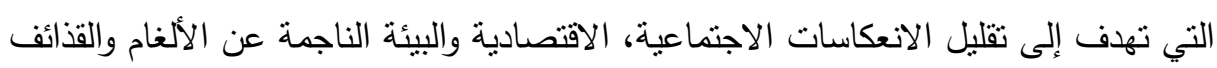
غير المنفجرة ( دليل مركز جنيف الدولي لإزالة الألغام من اجل الإنسانية)

\section{مسور الهمبه}

اقتصرت الدراسة على مدى كفاءة إدارة منظومة الأعمال المتعلقة بمكافحة الألغام في

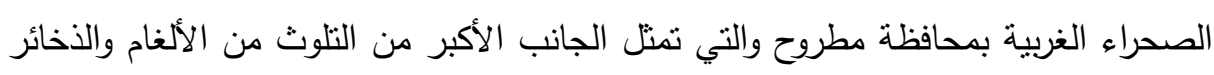

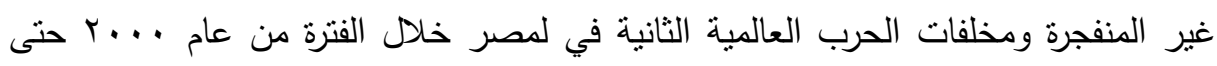
. r.IV

\section{أكوايت المهمث}

يستخدم الباحثون الطرق آلاتية لجمع البيانات والمعلومات من مجتمع العينة ومن

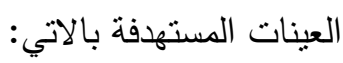


() زيارات مختلفة بالتتسيق مع مشروع الأمانة التنفيذية لإزالة الألغام إلى فريق الإزالة التابع للقوات المسلحة خلال تفقد وزيرة التعاون الدولي ووفد من برنامج الأمم المتحدة الإنمائي

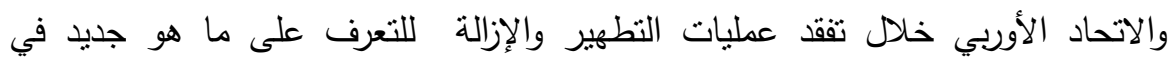
الأنشطة المتعلقة بعمليات نطهير الألغام ومخلفات الحرب الاتب

r) مقابلات مع مسئولين من القوات المسلحة وأعضاء اللجنة القومية للإثراف على لفئ إزالة الألغام وتتمية الساحل الثمالي الغربي، وكذلك أعضاء الأمانة التتفيذية لإزالة الألغام

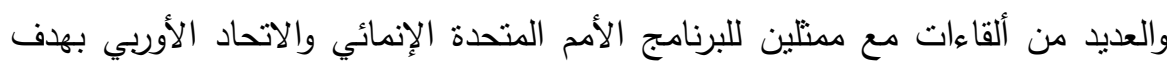
تجميع أداة الدراسة ( الاستبيان).

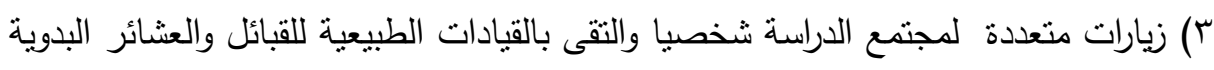
القاطنة في ربوع الصحراء حيث المناطق الملوثة بالألغام في مركز السلوم وسيدي برانى

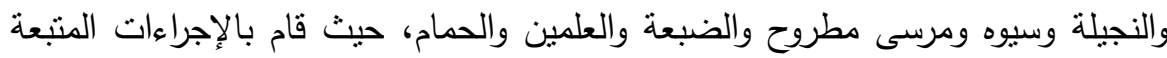

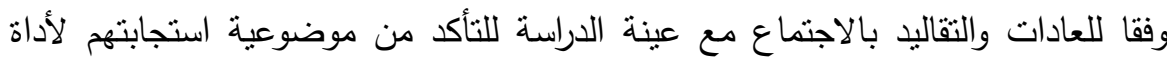
الدراسة ( الاستبيان) وذللك من خلال مجلس العمد والمشايخ والعواقل والحكماء والمنوط لهم المساهمة في دعم وحل الإشكاليات ذات الطباع الاجتماعي والإنساني والسياسي وفقاء للعادات والتقاليد في مناسبات تجمعهم استخدم الباحث طريقة ( كرة التلج ) في استكمال تجميع أداة الدراسة ( الاستنيان ) ) ع) تحليل استمارات الاستبيان واستتباط النتائج. 0) وضع إطار مفترح لأثر كفاءة ألإدارة الإدارة لمنظومة الأعمال المتعلقة بالألغام .

\section{الصراسايت المايرية}

ا-دراسة إيناس مصطفى محمود(ب ( + ب) بعنوان :" المسؤولية الدولية عن زراعة

\section{الألغام في ضوء القانون الإنساني}

عرض للمشكلة من الناحية القانونية البحتة تتمثل في مدى أمكانية المطالبة الدولية لمصر للدول التي زرعت الألغام في أراضى الغير خاصة التي تحاربت على ارض مصر أبان الحرب العالمية الثانية. 
توصلت إلى ضرورة توحيد الجهود في مواجهة الألغام من خلال إعادة النظر في القانون

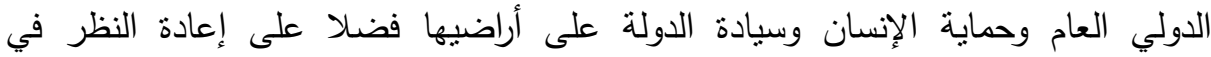
الاتفاقيات والمعاهدات ذات الصلة حتى تتشمل عدالة اجتماعية لكافة الدولة على هذا الكوكب

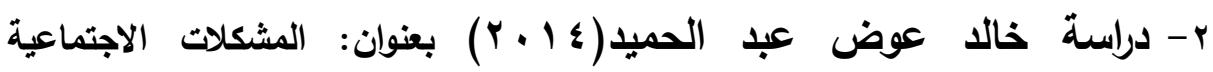
والقيزيقية المرتبطة بألغام العلمين ودور الجهود الرسمية وغير الرسمية في مواجهتها هدفت الدراسة إلى محاولة تقديم فهم سوسيولوجي للآثنار السلبية لمشكلة الألغام من الناحية فئه الاجتماعية وتقديم الحلول للتغلب عليها ومكافحتها ـ حيث كان مركز العلمين وهو احد مراكز محافظة مطروح الثمانية محل الدراسة تطرق الباحث أيضا إلى عرض الآثار السلبية لمشكلة

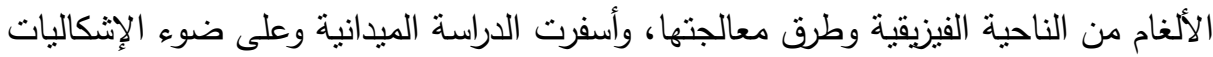

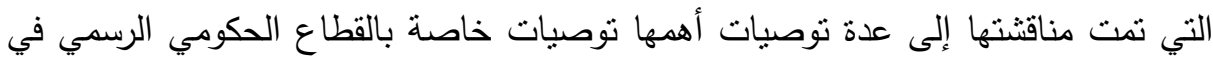

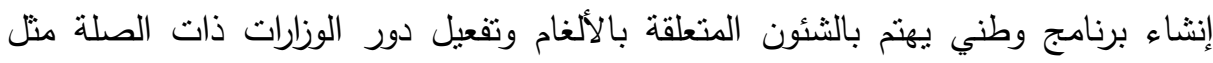

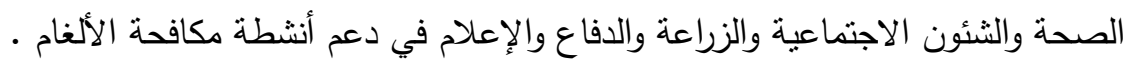

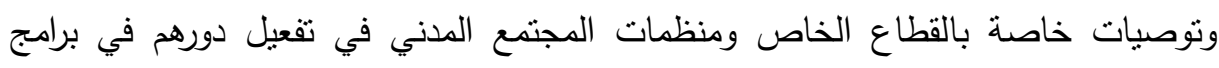
التوعية ودعم وتأهيل المصابين وأسرهم.

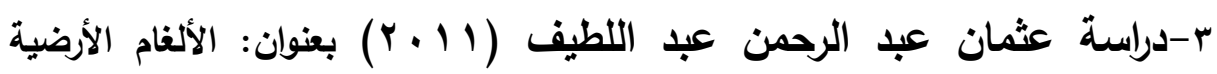
والمسؤولية الدولية بين القانون الدولي العام والثريعة الإسلامية دراسة مقارنة هدفت الدراسة إلى محالة تقديم فهم للمسئولية الدولية من خلال مقارنة بين القوانين

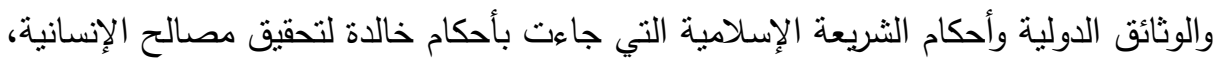
فان قضية الألغام تشتمد أهميتها من المفهوم الإسلامي من أحكام الثريعة الإسلامية التي الإني

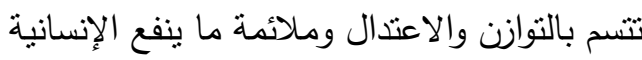
وتوصلت الدراسة إلى ضرورة مساءلة الدول عن أعمالها طبقا للقواعد القانونية ومبادئ القانون الدولي وعن مسؤوليتها في زراعة الألغام في أراضى الغير ومن ثم مطالبة مصر اعمره بالحق في التعويض وإصلاح الضرر . 
تعقيب علي الدراسات السابقة: باستعراض الباحث للدراسات السابقة يتضح ما يلي:أن كل

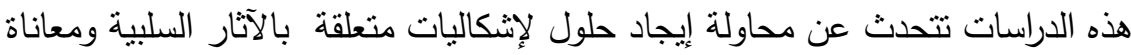

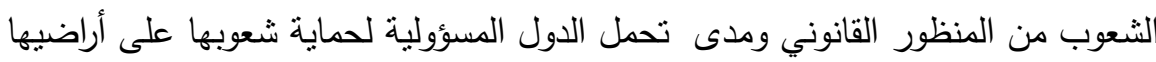

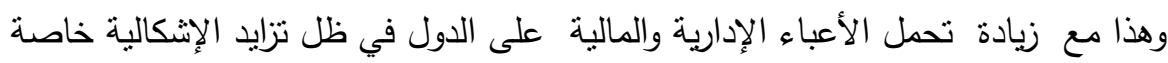
بعد ثورات الربيع العربي.

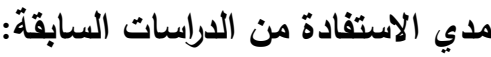
(1) هذه الدراسات ساعدت الباحث علي الاختيار الدقيق للمشكلة البحثية ومن ثم عنوانها حيث

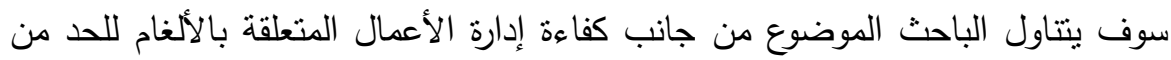
الأضرار البيئية حيث لم تتتاول أي دراسة هذا الموضوع من قبل في حدود علمه. r) استفاد الباحث من هذه الدراسات في صياغة الفروض الخاصة بدراسته وتحديد المنهج للاراسة والأدوات الملائمة لها وأساليب المعالجة الإحصائية وأهم النتائج لمقارنتها بنتائج البحث الحالي مما يساعد على توضيحها وتقسيرها.

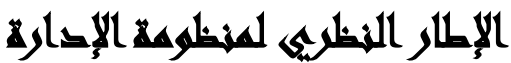

مفهوم المنظومة: يرتبط مفهوم المنظومة بطريقة التفكير لتتاول أي مجموعة من المركبات المرتبطة معا ومنها المؤسسات والتظظيمات الإدارية مع المشاكل المتعلقة بها بصورة شاملة، وهو يضم أيضاً مجموعة من التقنيات والأدوات والوسائل التي تساعد على حل هذه المشاكل.

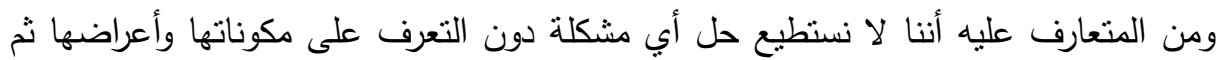

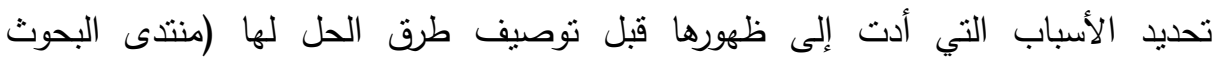
(الجامعية).

مفهوم الإدارة: تعتبر الإدارة عملية تحقيق الأهداف المرسومة باستغلال الموارد المتوفرة والمتاحة، وفق منهج مُحدّد وضمن بيئة معينة، كما تعتبر أيضًا عملية تخطيط وتتظيم وتتسيق وتوجيه ورقابة على الموارد المادية والبشرية بغية الوصول إلى أفضل النتائج بأقصر الطرقيه لمانه

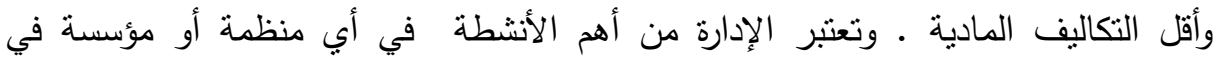


المجتمع، على أساس اختلاف مراحله، تطوره، وذلك لما للإدارة من تأثثر علي حياة

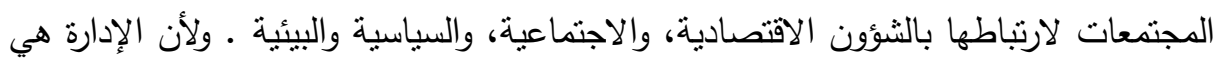

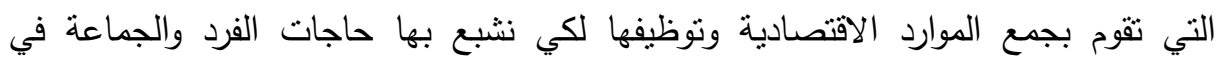
المجتمع. فبالإدارة يصنع التقدم الاجتماعي، وعليها تعتمد الدول في تحقيق التقدم والرخاء

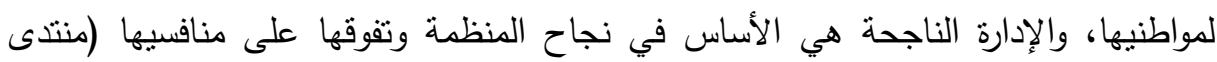

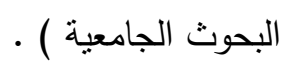

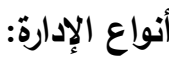
الإدارة العامة: تعثبر الإدارة العامة كونها تعمل في ظروف احتكارية تؤدي خدمات عامة

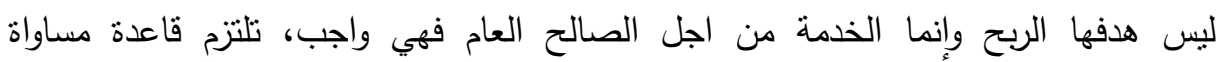

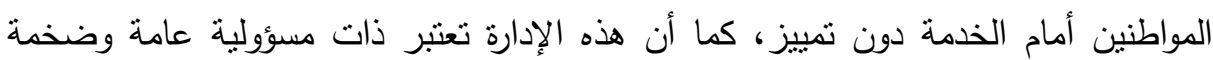
يشارك فيها عد كبير من الموظفين. إدارة الأعمال: تعرف بأنها تثميز بروح المنافسة الحادة كما أن هدفها الأسمى هو تحقيق

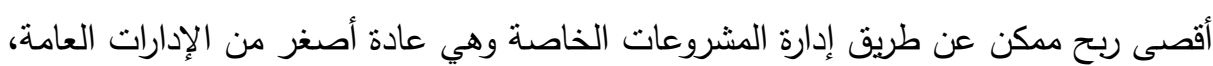

$$
\text { وفيها عدد محدود وقليل من الموظفين • }
$$

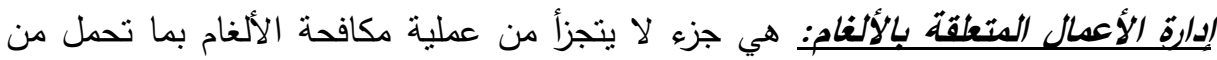

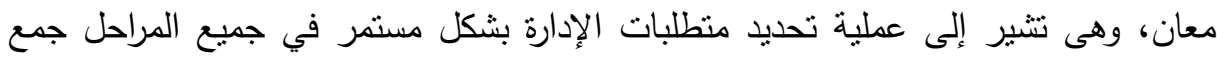
وتحليل البيانات والمعلومات في الوقت المناسب للجهات المعنية بالأعمال المتعلقة بالألغام ووهذا يتضمن الدعم للمنظمات غير المعنية بالإعمال المتعلقة بالألغام مثل المانحين والسياسيين والموظفين ورجال القانون والباحثين والجهات الفاعلة في أنثطة التتمية ،إدارة المعلومات الفاعلة تضمن للمدراء والجهات المعنية بالإعمال المتعلقة بالألغام الوصول إلى أفضل السياسات ومن ثم في اتخاذ القرارات ،وهذا يتطلب التعاون الوثثق بين جميع الأطراف بالِ المشاركة في إدارة الأعمال المتعلقة بالألغام حتى تكون فعالة وسهلة وعملية في مجال مكافحة

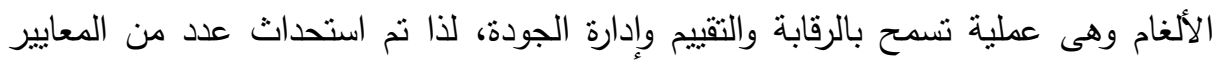

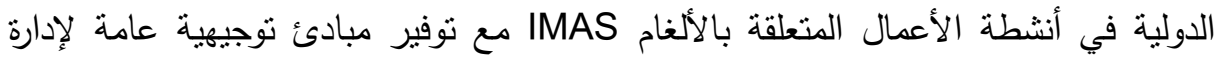


الأعمال في مجال مكافحة الألغام ،وهذه الوثيقة تساعد السلطات الوطنية في الدول المتضررة

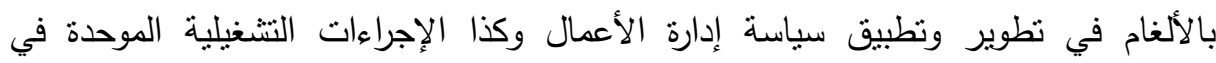
مشروعات مكافحة الألغام ( دليل مركز جينيف الدولي لإزالة الألغام من اجل الإنسانية ( $) \cdot$.

دائرة الأمم المتعدة للأعمال المتعقة بالألغام: وهى القسم التابع لإدارة عمليات حفظ السلام

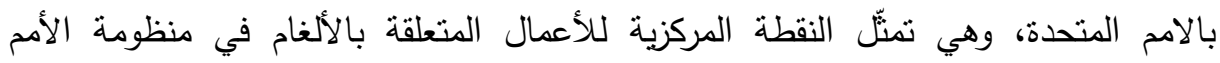

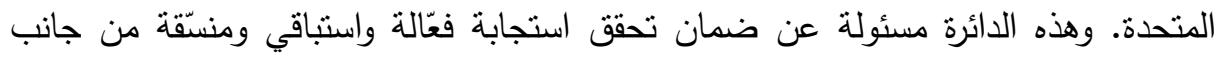

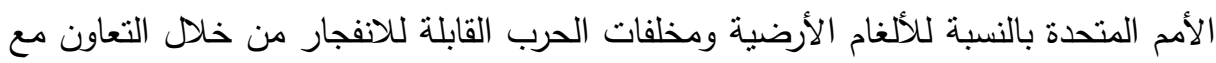
إدارات ووكالات وصناديق وبرامج من الكيانات الأخرى التابعة للأمم المتحدة عددها بات بال كياناً. وفي ظروف حفظ السلام والظروف الطارئة تتولى دائرة الأمم المتحدة للأعمال المتعلقة

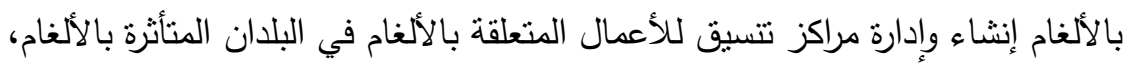

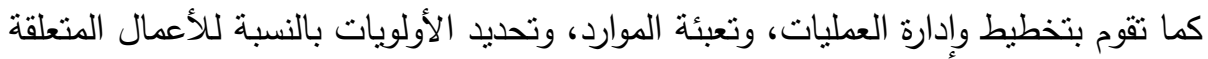
بالألغام في البلدان والمناطق التي تعمل فيها ( إدارة شؤون الإعلام، الأمم المتحدة)

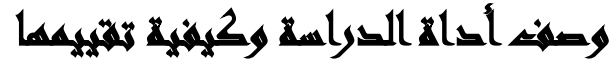

استخدم الباحث الاستبانة كأداة للاراسة في جمع البيانات والمعلومات ووجهت إلى عينة البحث وقد اشتملت على الأتي: 1-القسم الأول: هو عبارة عن السمات الثخصية عن المستجيب (الاسم، السن، النوع "ذكر/أنثي"، المؤهل نوعية التعليم الجامعي "حكومي/خاص"،حسل الاول الإقامة ونوعية الإقامة "

$$
\text { حضر / بدو، جهة العمل، مصدر الدخل الثهري) }
$$

r-القسم الثاني: وهو عبارة مجموعة من التساؤلات التي تحقق فروض الدراسة ويتكون الاستبيان من (דب) فقرة موزعة على أكثر من مقياس وكما يلي:

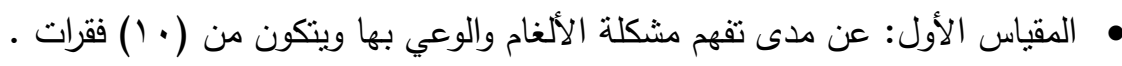

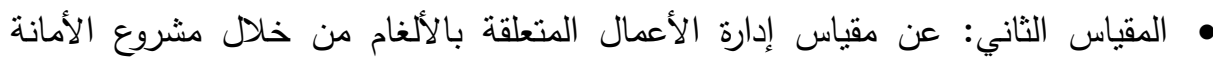

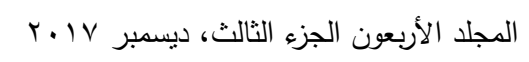


م المقياس الثالث: الأضرار والخسائر ويتكون من (9) فقرات

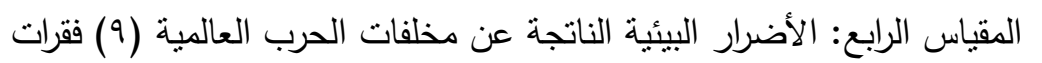

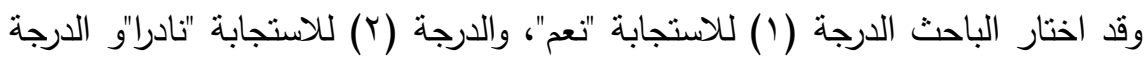

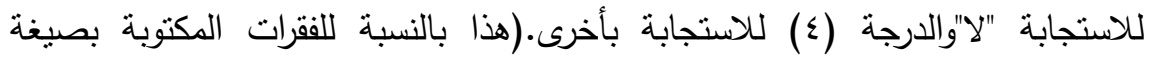
(ايجابية). • إجراءات تطبيق أداة الدراسة: مأولا: قياس الاعتمادية (الثبات والصدق للاسنتيان) • مثات الاستقصاء لعينة الطلبة: • للتحقق من ثبات الاستقصاء استخدم الباحث معادلة ألفا كرونباخ (Alpha Cranach)، ويوضح الجدول النالي معاملات الثبات الناتجة باستخدام هذه المعادلة. جدول رقم(1): ثبات العبارات لأبعاد الكقياس

\begin{tabular}{|c|c|c|}
\hline معامل ثبات ألفا & عدد العبارات & أبعاد الاستقصاء \\
\hline ..v.7 & 1. & مدى تقهر مشكلة الألغام والوعي بها \\
\hline$. . V \leqslant \Lambda$ & $\Lambda$ & مقياس إدارة الأعمال المتعلقة بالألغام \\
\hline..$V T T$ & 9 & الاضضرار والخسائر \\
\hline..$\wedge \Sigma \wedge$ & 9 & الأضرار البيئية \\
\hline
\end{tabular}

• بتضح من الجدول السابق أن قيم معاملات الثبات لأبعاد المقياس قيم مرتقعة حيث كانت

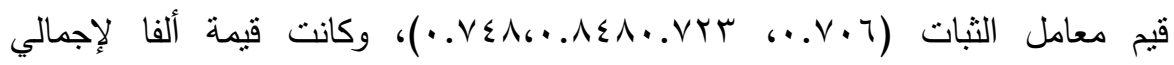

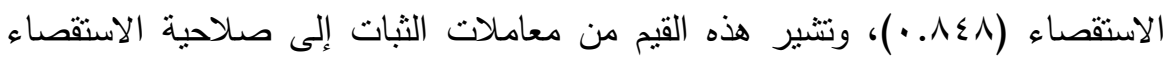
اللتطبيق وإمكانية الاعتماد على نتائجه والوثثق بهاه

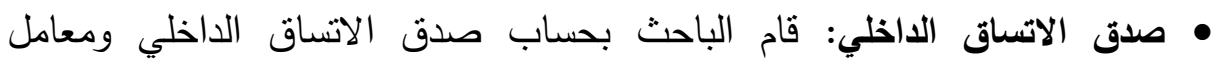
الارتباط المصح لكل محور بإجمالي الاستقصاء لحساب الصدق كالآتي: 
جدول رقم(ץ): ثبات العبارات لأبعاد المقياس

\begin{tabular}{|c|c|c|}
\hline معامل الصدق & \multicolumn{2}{|c|}{ أبعاد الاستقصاء } \\
\hline$(* *) \cdot . \wedge 17$ & معامل ارتباط بيرسون & \multirow{2}{*}{ مدى تقهم مشكلة الألغام والوعي بها } \\
\hline$\cdots+1$ & الدلالة المعنوية & \\
\hline$(") . .1 \vee 0$ & معامل ارتباط بيرسون & \multirow{2}{*}{ مقياس إدارة الأعمال المتعلقة بالألغام } \\
\hline$\ldots 1$ & الدلالة المعنوية & \\
\hline (")". . .57r & معامل ارتباط بيرسون & \multirow{2}{*}{ الأضرار والخسائر } \\
\hline$\ldots r$ & الدلالة المعنوية & \\
\hline ("). . . & معامل ارتباط بيرسون & \multirow{2}{*}{ الأضرار البيئية } \\
\hline$\cdots \cdots$ & الدلالة المعنوية & \\
\hline
\end{tabular}

• من الجدول السابق لصدق الاتساق الداخلي السابق لأبعاد المقياس نجد أن قيم معامل

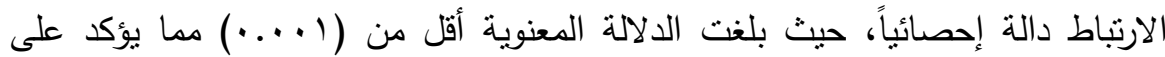

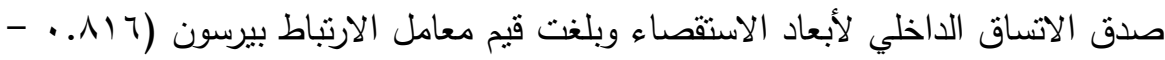

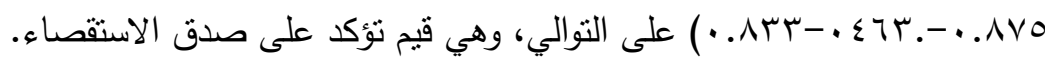

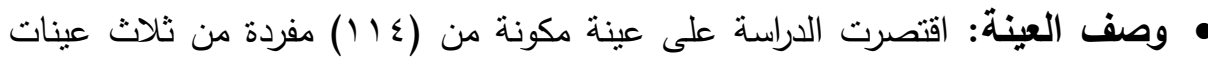
من المجتمع متمثلة في: ( العينة الأولى القيادات الطبيعية للمجتمع من خلال مجلس منس رنس العمد والمشايخ والحكماء لمحافظة مطروح والعينة الثانية تتمثل في القيادات التتفيذية

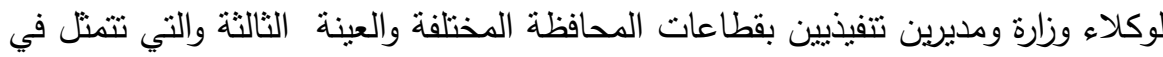
عدد من الجمعيات الأهلية العاملة في مجال مكافحة الألغام بمحافظة مطروح ).

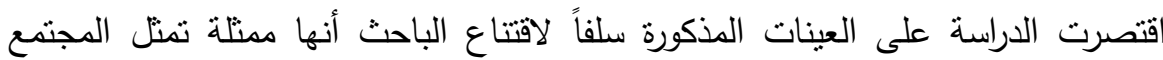
بكافة مراكزه وشرائحه والأكثر احتكاكا بالمجتمعات الملوثة بالألغام ومخلفات الحرب

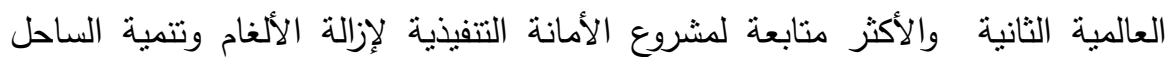

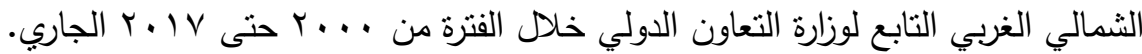

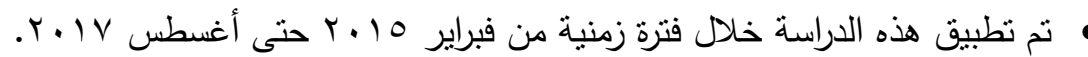




\section{(النجائية}

وكانت نتائج الدراسة الميدانية لـ "كفاءة الإدارة لمنظومة الأعمال المتعلقة بالألغام للحد من الأضرار البيئية " في ضوء الفرض الأنسانه

وجود تأثير سلبي للألغام والذخائر غير المنفجرة والمتروكة من مخلفات الحربه الحرب العالمية الثانية بالصحراء الغربية على البيئة الصحراوية وعلى الكائن الحي بشكل كامل. التحليل الإحصائي: نم تفريغ البيانات عن طريق البرنامج الإحصائي المعروف برنامج

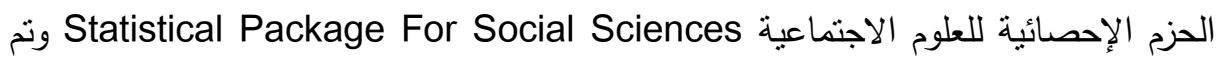
SPSS V. التحليل الإحصائي باستخدام الحاسب الآلي من خلال برنامج الحزم الإحصائية

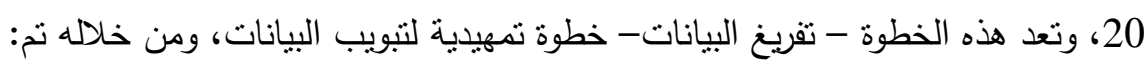

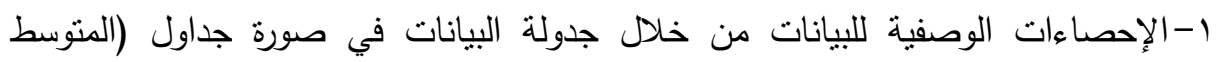

$$
\text { الحسابي والانحراف المعياري) لـتغيرات الدراسة. }
$$

ץ-تحليل الانحدار البسيط والانحدار المتعدد لدراسة تأثثر الألغام والذخائر غير المنفجرة والمتروكة من مخلفات الحرب العالمية الثانية بالصحراء الغربية على البيئة الصحراوية

$$
\text { وعلى الكائن الحي بشكل كامل. }
$$

وصف البيانات الديموجرافيه للاستقصاء:

\begin{tabular}{|c|c|c|c|c|}
\hline \multicolumn{2}{|c|}{ الأنثى } & \multicolumn{2}{|c|}{ الأكر } & \multirow{2}{*}{ المتغيرات } \\
\hline النسبة & العدد & النسبة & العدد & \\
\hline$\varepsilon \cdot . \varepsilon$ & $\varepsilon 7$ & 09.7 & 71 & النوع (الجنس) \\
\hline
\end{tabular}

جدول( ) : توزيع عينة الدراسة تبعاً لمتغير النوع (الجنس)

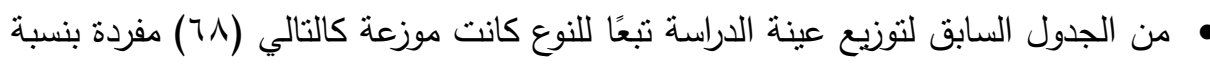

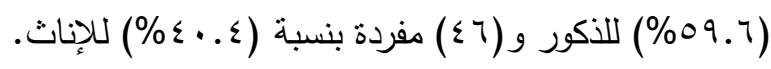


جدول(ץ): نوزيع عينة الدراسة تبعاً لمتغير المؤهل العلهي

\begin{tabular}{|c|c|c|c|c|c|c|c|c|c|c|c|c|}
\hline \multicolumn{2}{|c|}{ دراسات عليا } & \multicolumn{2}{|c|}{ مؤهل جامعي } & \multicolumn{2}{|c|}{ مؤهل فوق } & \multicolumn{2}{|c|}{ متوسط مؤل } & \multicolumn{2}{|c|}{ إعادي } & \multicolumn{2}{|c|}{ لم يجيب } & \multirow{2}{*}{ المتغيرات } \\
\hline النسبة & العدد & النسبة & العدد & النسبة & العدد & النسبة & العدد & النسبة & العلد & النسبة & العدد & \\
\hline V & $\Lambda$ & $\varepsilon \varepsilon . V$ & 01 & $\varepsilon . \varepsilon$ & 0 & $\Lambda . \Lambda$ & 1. & 1.1 & $r$ & r.T. & 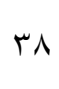 & الدراسوي \\
\hline
\end{tabular}

من الجدول السابق لتوزيع عينة الدراسة تبعًا للمؤهل العلمي كانت موزعة كالتالي(1)

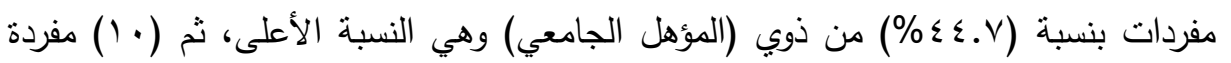

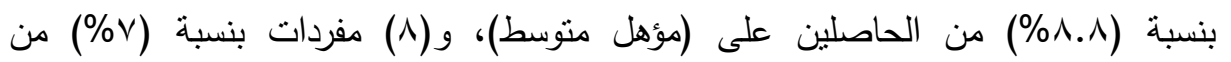
الحاصلين على (دراسات عليا). جدول(ץ): توزيع عينة الدراسة تبعاً لمتغير محل الإقامة

\begin{tabular}{|c|c|c|c|c|}
\hline \multicolumn{2}{|c|}{ بلو } & \multicolumn{2}{|c|}{ حضر } & \multirow{2}{*}{ المتغيرات } \\
\hline النسبة & العدد & النسبة & العدد & \\
\hline $0 \leqslant . \varepsilon$ & $7 r$ & $\leqslant 0.7$ & Or & محل الإقامة \\
\hline
\end{tabular}

من الجدول السابق لتوزيع عينة الدراسة تبعًا لمتغير محل الإقامة كانت موزعة كالتالي

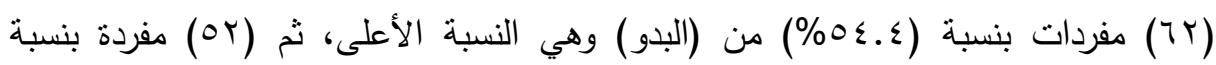

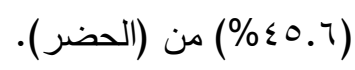

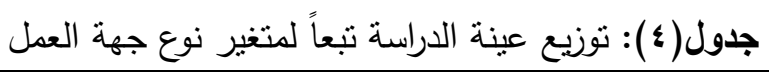

\begin{tabular}{|c|c|c|c|c|c|c|}
\hline \multicolumn{2}{|c|}{ منظمات مجتمع } & \multicolumn{2}{|c|}{ قيادات تنفيذية } & \multicolumn{2}{|c|}{ مجلس المشايخ وإلّحكماء } & \multirow{2}{*}{ المتغيرات } \\
\hline النسبة & العدد & النسبة & العدد & النسبة & العدد & \\
\hline$\varepsilon r$ & $\sum 9$ & $\varepsilon r . q$ & 0. & $1 T . Y$ & 10 & جهة العمل \\
\hline
\end{tabular}

من الجدول السابق لتوزيع عينة الدراسة تبعًا لنوع جهة العمل كانت موزعة كالتالي (•) (ه)

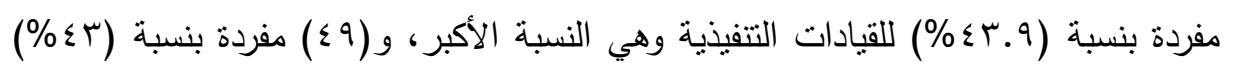

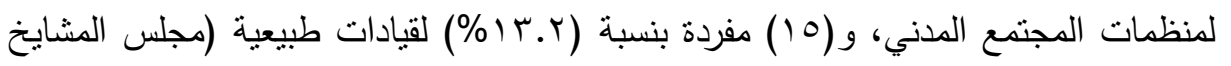
والحكماء). 
تحليل الانحار البسيط للتحقى من صحة الفروض: وجود تأثثر سلبي للألغام والذخائر غير المنفجرة والمتروكة من مخلفات الحرب العالمية الثانية بالصحراء الغربية على البيئة الصحراوية وعلى الكائن الحي بشكل كامل جدول(•): التحديد لاختبار الانحدار البسيط لمدى تأثير مشكلة الألغام والوعي بها على بلى

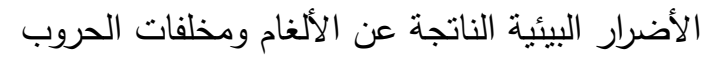

\begin{tabular}{|c|c|c|c|c|c|c|c|c|}
\hline المعنوية & قيمة & 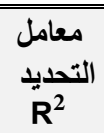 & $\mathbf{R}$ & المعنوية & قيمة ت & قيتًا & الانحدار & المتغيرات \\
\hline$\ldots \wedge$ & $r .971$ & דr. &. .171 & $\ldots \lambda$ & 1.VKT & .01 .1 & Tr.VYI & مشكلة الألغام \\
\hline
\end{tabular}

يتضـح من الجدول السابق لتحليل الانحدار الخطي البسيط نجد أن قيمة معامل الارتباط

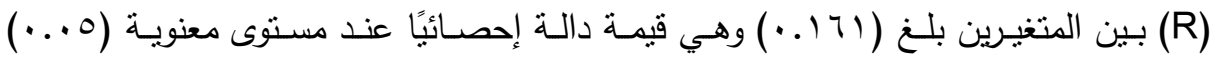
وكانت مستوى المعنوية للعلاقة ( ( . . ·)، ومن خلال نتائج معامل التحديد (R2) للانحدار نجد أن هنالك مشكلة الألغام والوعي بها على الأضرار البيئية الناتجة عن الألغام ومخلفات

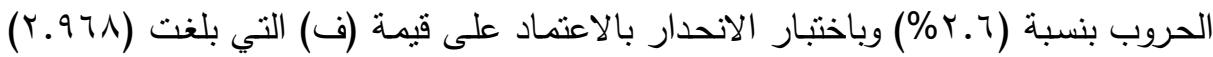

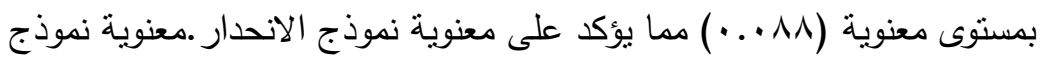
تم من خلال النموذج اختبار معنوية معامل الانحدار (B) والذي يوضح وجود علاقة بين

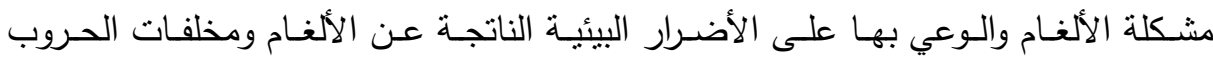

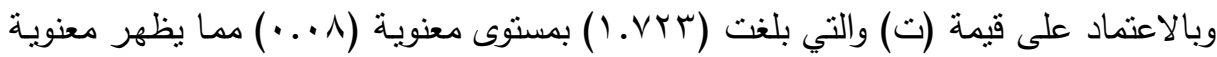

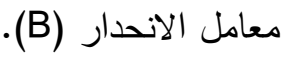
يوجد تأثثر لمشكلة الألغام والوعي بها على الأضرار البيئية الناتجة عن الألغام ومخلفات

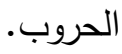


جدول(؟): التحديد لاختبار الانحدار لمدى تأثثر إدارة الأعمال المتعلقة بالألغام في مشروع مكافحة

\begin{tabular}{|c|c|c|c|c|c|c|c|c|}
\hline المعنوية & قيمة & التحديد معامل & $\mathbf{R}$ & المعنوية & قيمة ت & قيتية & معاملات & المتغيرات \\
\hline$\ldots \varepsilon$ & $\varepsilon . r \leqslant$. & $\ldots r v$ & r & $\ldots \varepsilon$ & r..AT & .1 .4 & rT.A.r & فالألمالعمال \\
\hline
\end{tabular}

يتضح من الجدول السابق لتحليل الانحدار الخطي البسيط نجد أن قيمة معامل الارتباط

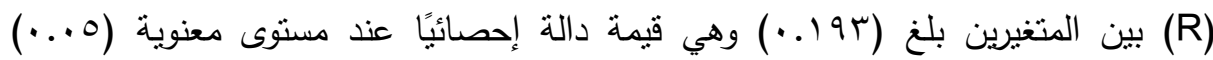
وكانت مستوى المعنوية للعلاقة ( ( . ..)، ومن خلال نتائج معامل التحديد (R2) للانحدار نجد أن هناك مشكلة الألغام والوعي بها على الأضرار البيئية الناتجة عن الألغام ومخلفات

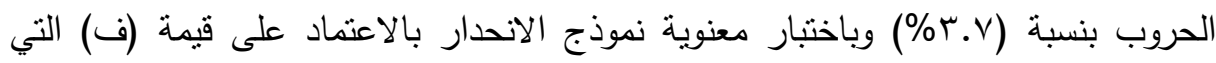

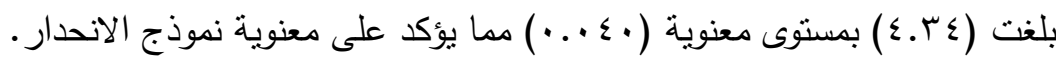

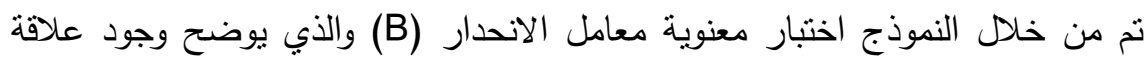

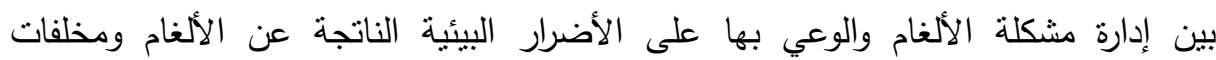

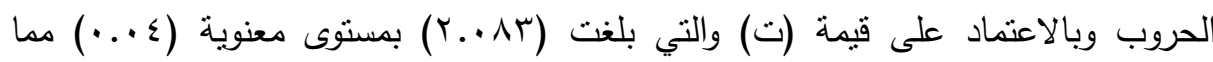
يظهر معنوية معامل الانحدار (B). يوجد تأثير لإدارة مشكلة الألغام والوعي بها على الأضرار البيئية الناتجة عن الألغام ومخلفات الحروب. 
جدول(V): التحديد لاختبار الانحدار البسيط لمدى تأثثر الأضرار والخسائر على الأضرار

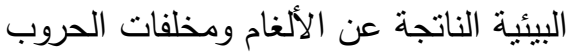

\begin{tabular}{|c|c|c|c|c|c|c|c|c|}
\hline المعنوية & قيمة ف & 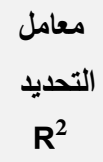 & $\mathbf{R}$ & المعنوية & قيمة ت & قييتا & الاندار & المتغيرات \\
\hline$\cdots$ & $\mid \wedge . \wedge \leqslant T$ & $. .1 \leq \varepsilon$ & . rvq & $\ldots$ & $\varepsilon . r \varepsilon 1$ & 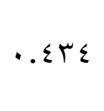 & $1 \leq . V 19$ & والخسائر \\
\hline
\end{tabular}

يتضح من الجدول السابق لتحليل الانحدار الخطي البسيط نجد أن قيمة معامل الارنباط

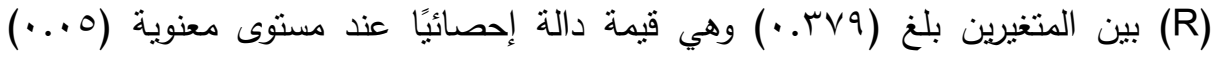
وكانت مستوى المعنوية للعلاقة ( ( ....)، ومن خلال نتائج معامل التحديد (R2) للانحدار

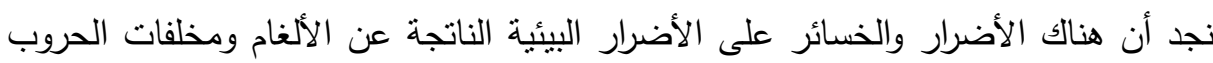

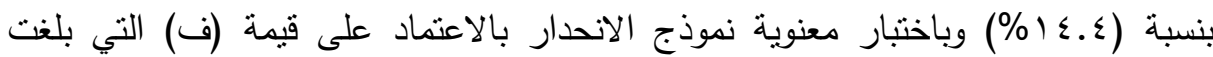

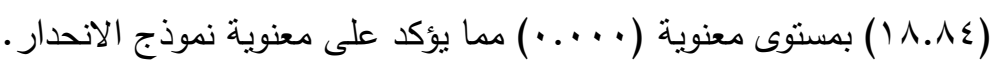
تم من خلال النموذج اختبار معنوية معامل الانحدار (B) والذي يوضح وجود علاقة بين

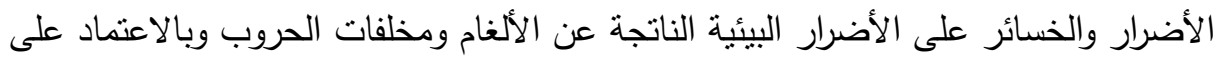

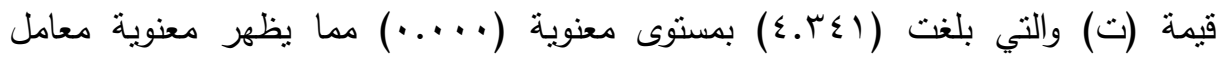
الانحدار (B) يوجد تأثثر للإضرار والخسائر على الأضرار البيئية الناتجة عن الألغام ومخلفات الحروب. 
تحليل الاتحدار المتعدد: جدول رقم(1): اختبار الانحدار المتعدد لتأثثر كفاءة الإدارة لمنظومة الأعمال المتعلقة بالألغام للحد من الأضرار البيئية

\begin{tabular}{|c|c|c|c|c|c|c|}
\hline التحديد & $\begin{array}{c}\text { الارتباط } \\
\text { معامل } \\
\text { (R) }\end{array}$ & قيمة ف & مستوى المعنوية & قيمة ت & معامل & المتغيرات \\
\hline \multirow{4}{*}{. .104} & \multirow{4}{*}{.$r q}$. & \multirow{4}{*}{$7.0 \mathrm{VT}$} & $\ldots \ldots$ & $0.1 \leq 9$ & I E.TVV & الثابت \\
\hline & & &.$\vee \vee \vee q$ & $\begin{array}{c}- \\
. r \wedge r\end{array}$ & $\ldots r \cdot-$ & والأضرار البيئية الناتجة عنلة الألغام والوعي بها على الألغام \\
\hline & & & . & $.9 \vee \wedge$ &. .01 & فالألغاثمير إدارة الأعمال المتعلقة بالألغام \\
\hline & & & $\ldots \ldots$ & T.V৭V &..$\leqslant 11$ & 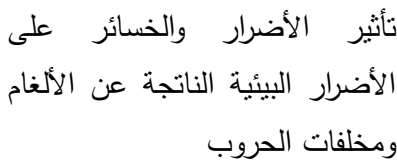 \\
\hline
\end{tabular}

لاراسة تأثنر سلبي للألغام والذخائر غير المنفجرة والمتروكة من مخلفات الحرب العالمية الثانية بالصحراء الغربية على البيئة الصحراوية وعلى الكائن الحي بشكل كامل تبين من نتائج

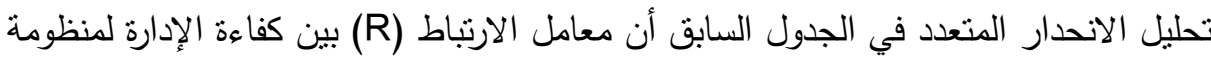

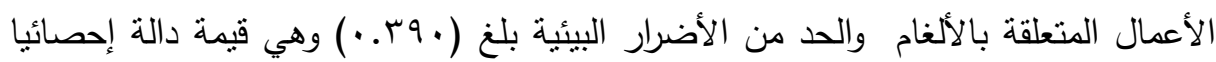
عند مستوى معنوية (0...)، لذا توجد علاقة ارتباط بين كفاءة الإدارة لمنظومة الأعمال المتعلقة بالألغام والحد من الأضرار البيئية. 
من خلال نتائج الجدول السابق معامل التحديد (R2) للانحدار في نجد أن هناك تأثير

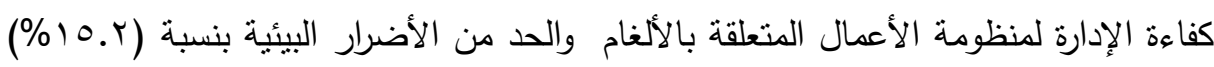

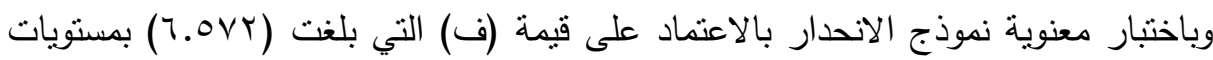

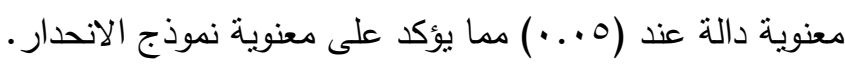

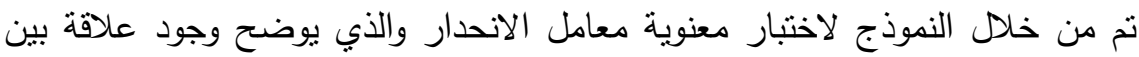

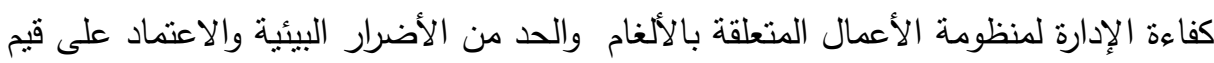
(ت) بمسنويات معنوية دالة عند (0. ..) مما بظهر معنوية معامل الانحدار وبالتالي إمكانية الاعتماد على المتغيرات المستقلة للتنبؤ بالتغير في الأضرار البيئية، وكانت معادلة الانحدار :

$$
\mathrm{Y} 1=14.677+-0.020 \times 1+0.058 \times 2+0.411 \times 3
$$

لذلك يثبت صحة الفرض : وجود تأثثر سلبي للألغام والذخائر غير المنفجرة والمتروكة من مخلفات الحرب العالمية الثانية بالصحراء الغربية على البيئة الصحراوية وعلى الكائن

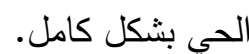

\section{النيوكياتي}

\section{( ) توصيات على مستوى مصر:}

- إنشاء مركز وطني للأعمال المتعلقة بالألغام معتمد تابع لرئاسة مجلس الوزراء على أن

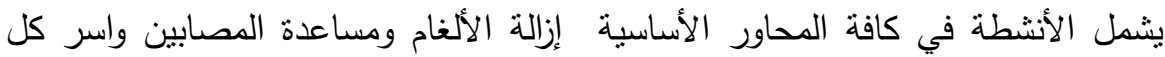

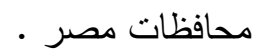

- نطبيق المعايير والإجراءات الدولية للأعمال المتعلقة بالألغام - مشاركة وزارة الصحة ووزارة الثؤون الاجتماعية ووزارة البيئة في برامج الأعمال المتعلقة بالألغام - مشاركة المجلس القومي لحقوق الإنسان والمجلس للمعاقين والمجلس القومي للمرأة في أنشطة الأعمال المتعلقة بالألغام 
- ضرورة تعزيز دور منظمات المجتمع المدني في دعم أنشطة مساعدة الضحايا وبرامج

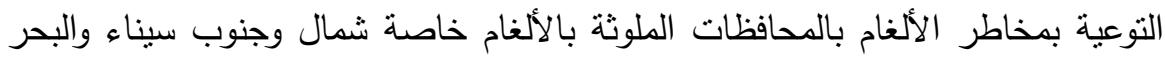

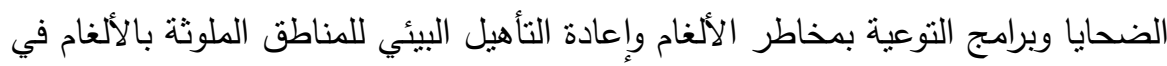
الأحمر والإسماعيلية ومطروح بما يتفق مع المعايير الدولية مع مراعاة البعد البيئي وملائمة احتباجات المجتمعات المتضررة. - أنثاء اتحاد نوعى للجمعيات العاملة في مجال مكافحة الألغام على مستوى مصر بالتعاون مع المركز الوطني للأعمال المتعلقة بالألغام

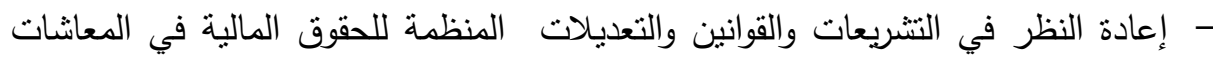
والمنح والإعانات الثهرية المصابين واسر الضحايا - إعادة النظر في تأهيل المستشفيات والوحدات الصحية بتزويدها بأطقم طبية مؤهلة وبمعدات وأجهزة طبية حديثة في مجال إصابات الألغام وخاصة أقسام الاستقبال والطوارئ

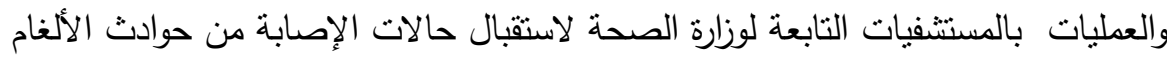
- موافقة القوات المسلحة على السماح في استقبال حالات الإصابة من للمدنيين والعلاج

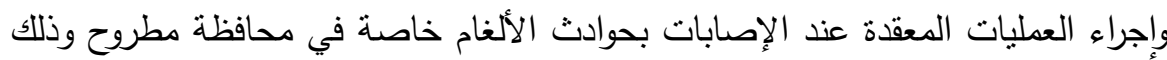
نظرا لازدياد الإصابة بسبب الهجرة غير الثرعية

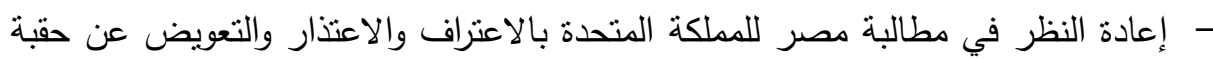

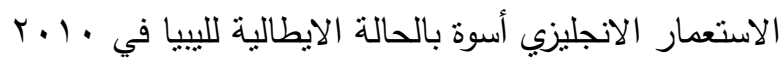

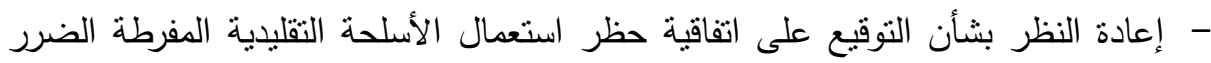

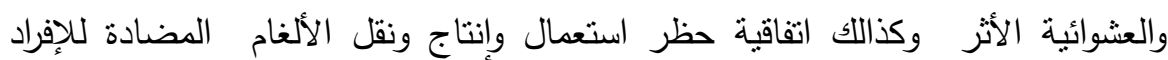
وتنميرها ץ-على المستوى العربي: ضرورة تبنى جامعة الدول العربية للقضايا المتعلقة بأثز الحروب على المجتمعات العربية في الدول العربية، من خلال أنثاء المركز العربي لمكافحة الألغام ومخلفات الحروب تابع لجامعة الدول العربية يمتل الكيان العربي الذي يجمع الإثكاليات الناتجة عن الحروب والنزاعات الإقليمية ويعمل على إيجاد الحلول المناسبة في المعالجات 
البيئية الناتجة عن مخلفات الحروب والأجسام القابلة للانفجار والأجسام المتروكة أثناء

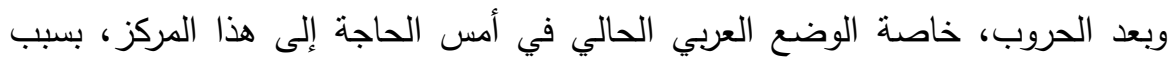

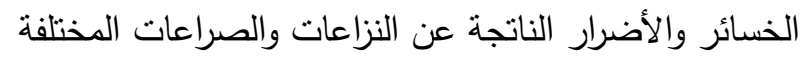

\section{المرالئ}

أحمد السيد أبو ألوفا(ץ .. ץ): المسئولية الدولية للدول واضعة الألغام في الأراضي الدصرية

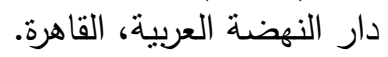

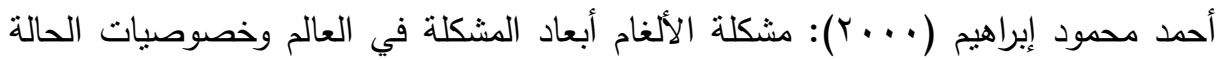

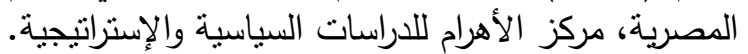

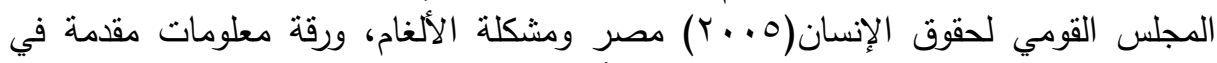

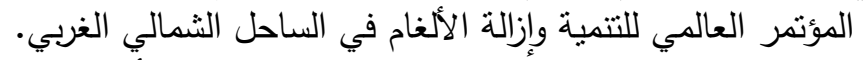

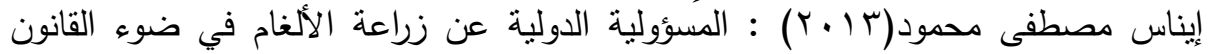
الإنساني جامعة عين شمس كلية الحقوق.

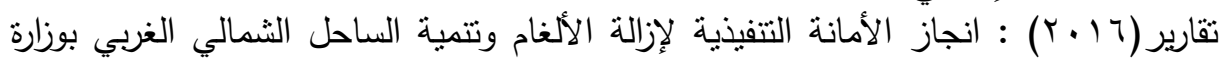

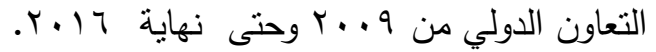

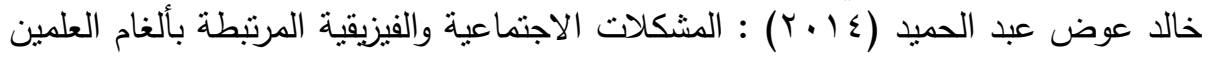

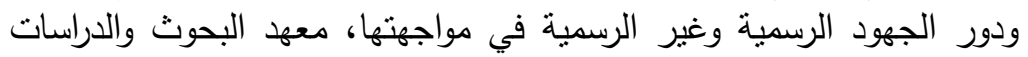

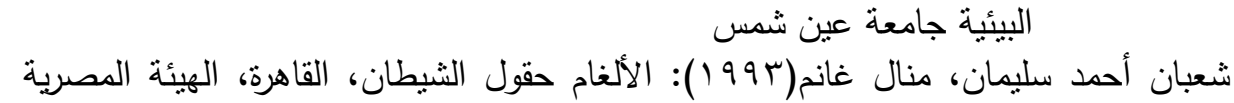

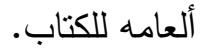

عثمان عبد الرحمن عبد اللطيف(1) (1) الألغام الأرضية والمسؤولية الدولية بين القانون

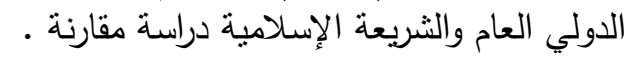

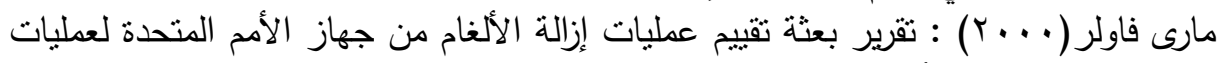
إزالة الألغام.

محمد عبد الحميد (991 (19)): "مناهج وإجراءات البحث العلمي"، الجزء الثاني، المكتب الجامعي

$$
\text { الحديث، الإسكندرية. }
$$

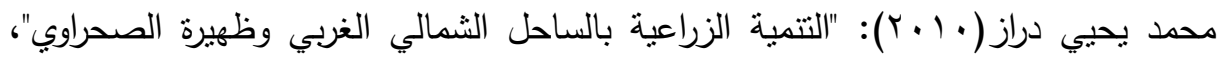

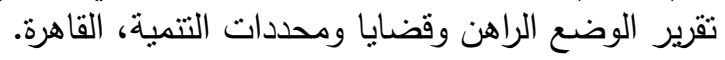

ملخص التتفيذي(· ( • ب): تحديث إستراتيجية وخطة التتمية الثاملة للساحل الثمالي الغربي

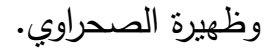


هبه المراسي(ع —.ب): نائب مساعد وزير الخارجية، قمة نبروبي لعالم خالي من الألغام (مؤتمر المراجعة الأول)، نيروبي.

Boutros Boutros Ghali, "The Land Mine Crisis: A Humanitarian http://armtrac.net/portfolio-view/a400-in-egypt/ http://www.fp7-tiramisu.eu/landmine-uxo-threats/landmines http://www.nato.int/cps/en/natohq/news_108818.htm Egyptian desert: new technologies for landmine detection http://www.un.org/News/dh/infocus/sudan/Mine_Action. https://landminesinafrica.wordpress.com/tag/egypt/ https://www.hrw.org/reports/1999/landmine/execsum/Execweb103.htm

https://www.unicef.org/emergencies/index_landmines.html https://www.usaid.gov/egypt/press-releases/oct-17-2016-us-embassypromotes-mine-action-northwest-coast-area resolution-on-mine-action

State Information Services, "Landmines in Egypt," 20 July 2009; and The Human Costs of landmines", Internatioanl Review of the red cross, 1 January, 1995, P. P. 3-4.

The international committee of the red cross (ICRC), Anti-Personnel United Nations \& UNICEF, Report of Graca Machel, Impact of Armed Conflict on Children, New Tork \& Paris, UNICEF, 1994, p. p. 50-52. 


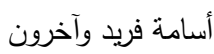

MANAGEMENT EFFICIENCY FOR LAND MINE

ACTION PROGRAMS TO REDUCE

ENVIRONMENTAL DAMAGES

Fareed, O. ${ }^{(1)}$; El-shahat, Nehal, F. ${ }^{(2)}$; Al-Shazly, M. F. ${ }^{(3)}$;

Al Kilani, M. ${ }^{(4)}$ and khalifa, A. A. ${ }^{(5)}$

1) Faculty of Commerce, Ain Shams University 2) Institute of Environmental Studies \& Research Ain Shams University. 3) Ministry of Foreign Affairs 4) Ministry of International Cooperation 5) Ministry of Electricity and Energy•

\begin{abstract}
The aim of the research is to attempt to present the management concept of the mine action system to reduce the environmental damage and losses resulting from it and to provide solutions to address it

The study sample consisted of (114) respondents divided into three of the study population. It consisted of 15 natural leaders from the council of mayors, sheikhs and wise men and 50 members from the sample of the executive leaders represented in the sector leaders. Of mine survivors through NGOs in the study area

The study was based on the social survey in the sample, where the social survey used is considered suitable for the analytical descriptive study

The study found several results, most notably the impact and relationship between the management efficiency of the mine action system and the reduction of environmental damage. The validity of the hypothesis is that there is a negative impact of mines and remnants of the Second World War in Western Sahara on the desert environment and the entire organism
\end{abstract}

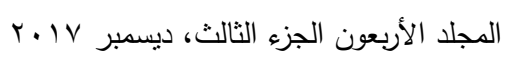


مجلة العلوم البيئية

معهد الدراسات والبحوث البيئية - جامعة عين شمس لهـ

The study recommends that the Egyptian mine action project be upgraded and developed to become a national mine action center in Egypt to be responsible for managing key elements of activities and all mine action, including clearance and clearance, victim assistance programs, victim families, MRE programs, Reviewing international conventions and treaties and enacting legislation and laws regulating all elements through sub-centers in governorates contaminated with mines, unexploded ordnance and explosive remnants of war throughout Egypt. 